\section{Nutrient Concentration and Fruit Thinning Affect Shelf Life of Long English Cucumber}

\author{
W.C. Lin and D.L. Ehret \\ Agriculture Canada, Research Station, P. O. Box 1000, Agassiz, B.C. \\ VOM 1AO, Canada
}

Additional index words. quality, postharvest, greenhouse, fertilization, fruit color, Cucumis sativus

\begin{abstract}
Long English cucumber (Cucumis sativus L.) plants were treated with one of three nutrient concentrations in combination with two fruit thinning treatments forming a $3 \times 2$ factorial greenhouse experiment. High nutrient concentration enhanced fruit color at harvest and prolonged shelf life but reduced marketable fruit per plant. Thinning of one-third of the fruit from the main stem and laterals had a similar effect. Cucumbers harvested from the upper canopy generally had longer shelf life than those from the lower canopy. Shelf life was correlated with fruit color at harvest.
\end{abstract}

Fruit color of long English cucumbers is an important factor indicating quality, and shelf life is often determined by days to incipient yellowing. Individual fruit vary widely in shelf life, which cannot totally be explained by postharvest conditions (Lin, 1989). The causes of this yellowing are not well understood, but a host of pre- and postharvest factors has been implicated (Grower, 1988).

Cucumber fruit color has been studied during fruit development (Kanellis et al., 1986; Saltveit and McFeeter, 1980) and postharvest handling (Kanellis et al., 1986; Poenicke et al., 1977), but the effect of production conditions on fruit color at harvest and color retention during postharvest storage is not well documented.

This experiment was conducted to 1) determine the effects of nutrient concentration and fruit load per plant on fruit color at harvest and subsequent shelf life, and 2) establish the relationship between fruit color at harvest and shelf life in greenhouse-grown long English cucumbers.

Seeds of 'Mustang' cucumber were sown individually in rockwool cubes on 23 Mar. 1989 and transplanted into 20-liter bags of sawdust (one plant per bag) on 13 Apr. at a density of 1.6 plants $/ \mathrm{m}^{2}$. Plants were grown in a greenhouse under natural light. Air temperatures were set at 22/19C (day/night), and air maxima/minima of $25.5 / 18.7 \mathrm{C}$ were recorded. The experiment was terminated on 2 Sept. 1989.

The experiment was $3 \times 2$ factorial with three nutrient concentrations and two fruit-

Received for publication 6 July 1990. Contribution no. 408 of Agassiz Research Station, Agriculture Canada. We thank John Hall, Vancouver Research Station, Agriculture Canada, Vancouver, B. C., for his helpful suggestions on statistical analysis. The study was partially supported by the B.C. Greenhouse Vegetable Research Council. The cost of publishing this paper was defrayed in part by the payment of page charges. Under postal regulations, this paper therefore must be hereby marked advertisement solely to indicate this fact. thinning regimes. The greenhouse was divided into nine plots with six plants per plot. Each plot received one randomly assigned nutrient concentration (three plots per nutrient concentration) and contained three thinned and three nonthinned plants.

The standard nutrient solution was based on the Nursery, Greenhouse Vegetables and Ornamental Production Guide for Commercial Growers (B.C. Min. of Agriculture and sisted of $14.45 \mathrm{NO}_{3}^{-}, 1.47 \mathrm{PO}_{4}^{-2}, 4.94 \mathrm{~K}+$, $5.49 \mathrm{Ca}^{+2}, 2.66 \mathrm{Mg}^{+2}$, and $2.66 \mathrm{SO}_{4}^{-2}$ in millimolar concentrations. The high, medium, and low nutrient concentrations were $150 \%, 100 \%$, and $50 \%$ of the standard solution, respectively. These three nutrient solutions contained the same micronutrient concentrations of $18.8 \mathrm{Fe}, 5.5 \mathrm{Mn}, 0.9 \mathrm{Zn}$, $0.2 \mathrm{Cu}, 18.1 \mathrm{~B}$, and $0.1 \mathrm{Mo}$, in micromolar concentrations. The final $\mathrm{pH}$ was adjusted to 6.3 to 6.6 with $\mathrm{H}_{2} \mathrm{SO}_{4}$. The electrical conductivity (EC) was measured with a conductance meter (YSI Model 32 Yellow Springs Instrument Co., Yellow Springs, Ohio). The average EC values, taken once a week over the experiment, were $2.81,1.95$, and $1.23 \mathrm{mS} \cdot \mathrm{cm}^{-1}$ in high, medium, and low nutrient solutions, respectively. All plants were irrigated with the same frequency and duration $(200 \mathrm{ml} /$ plant every 1 to $2 \mathrm{~h}$, depending on prevailing light levels). stem, nonthinned plants were allowed to bear one fruit per node. Thinned plants retained one fruit on two out of every three nodes, giving rise to a $30 \%$ reduction in fruit load compared with nonthinned plants. In both treatments, laterals were removed from these nodes. Fruit on the main stem were labelled with their node position, increasing from the bottom to the top of the canopy. Aborted and young deformed fruit were removed when apparent. Plants were topped at $2 \mathrm{~m}$ and allowed to grow one side shoot on each side. On each side shoot, the two first laterals were allowed to develop in thinned plants, and the three first laterals in nonthinned plants. LatFisheries Production Guide, 1988) and con-

Starting from the ninth node of the main erals were not fruit-thinned. Hence, the $30 \%$ difference in fruit load between treatments (originating from main stem fruit thinning) was maintained by a difference in the number of laterals rather than fruit count per lateral. When all fruit on a first lateral were harvested, a secondary lateral was allowed to replace the corresponding first lateral. All laterals were terminated $60 \mathrm{~cm}$ above the ground. Fruit on the first and second laterals were also labelled with node position increasing chronologically (in this case, node position increased from the top to the bottom of the canopy). Each fruit was tagged with date of anthesis. Fruit of marketable size (minimum $35.0 \mathrm{~cm}$ long and $4.3 \mathrm{em}$ in diameter) were harvested three times a week and averaged 35 to $40 \mathrm{~cm}$ long. Date of harvest, fresh weight, and fruit color at harvest were recorded for each fruit. A color photograph of nine cucumbers ranging from entirely yellow (score $=1$ ) to completely dark green (score $=9$ ) was used as a standard to visually assess fruit color at harvest.

Each harvested fruit was placed individually in a perforated polyethylene tube (48 $\times 13 \mathrm{~cm}$ ) with one end open. These tubes were used to prevent moisture loss but were not intended to modify the air composition around the fruit. Fruit were stored at $13.5 \mathrm{C}$ and $90 \%$ to $95 \%$ relative humidity for 3 weeks and observed every 2 days for incipient yellowing. Days to harvest was defined as days between anthesis and harvest, and shelf life as days between harvest and occurrence of incipient yellowing (color rating of 5).

A randomized complete-block design was used and analysis of variance was conducted for main effects and interactions using SAS statistical package (SAS Institute, Cary, N.C.). Shelf life was correlated with fruit color, days to harvest, and fresh weight, using a stepwise regression procedure. Level of significance is indicated when appropriate.

The highest nutrient concentration improved fruit color at harvest and the subsequent shelf life (Table 1). Fruit thinning improved shelf life and, to a lesser extent, improved the fruit color at harvest. High nutrient concentration and fruit thinning both

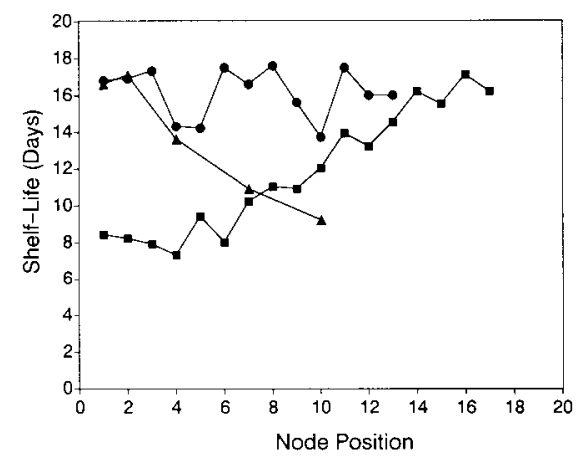

Fig. 1. Shelf life of cucumber fruit harvested from various nodal locations on main stem

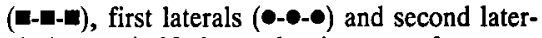
als $(\boldsymbol{\Lambda}-\boldsymbol{\Lambda}-\boldsymbol{\Lambda})$. Node number increases from canopy bottom to top on the main stem, and from canopy top to bottom on first and second laterals. 
Table 1. Effects of nutrient concentration and fruit thinning on days to harvest (days from anthesis to harvest), fruit color $(1=$ yellow; $9=$ green) at harvest, shelf life (days from harvest to incipient yellowing), and number of marketable cucumbers per plant ( $\mathrm{n}=54$ plants).

\begin{tabular}{|c|c|c|c|c|c|c|c|c|}
\hline \multirow{2}{*}{$\begin{array}{l}\text { Level of } \\
\text { nutrient concn }\end{array}$} & \multicolumn{2}{|c|}{ Fruit color (rating) } & \multicolumn{2}{|c|}{ Shelf life (days) } & \multicolumn{2}{|c|}{ Days to harvest } & \multicolumn{2}{|c|}{ Marketable fruits/plant } \\
\hline & Thinned & Nonthinned & Thinned & Nonthinned & Thinned & Nonthinned & Thinned & Nonthinned \\
\hline High & 6.7 & 6.7 & 17.2 & 16.0 & 14.2 & 15.5 & 23.3 & 26.3 \\
\hline Medium & 6.5 & 6.4 & 14.5 & 12.7 & 15.6 & 16.5 & 26.6 & 29.0 \\
\hline Low & 6.5 & 6.4 & 14.1 & 11.2 & 15.9 & 16.8 & 31.2 & 33.4 \\
\hline & \multirow{2}{*}{\multicolumn{2}{|c|}{0.0494}} & \multicolumn{2}{|c|}{0.6196} & \multirow{2}{*}{\multicolumn{2}{|c|}{0.2925}} & \multirow{2}{*}{\multicolumn{2}{|c|}{1.4652}} \\
\hline Significance & & & & & & & & \\
\hline Concn & \multicolumn{2}{|c|}{ *** } & \multicolumn{2}{|c|}{ *** } & \multicolumn{2}{|c|}{$* * *$} & \multicolumn{2}{|c|}{ *** } \\
\hline Thinning & \multicolumn{2}{|c|}{$*$} & \multicolumn{2}{|c|}{ **** } & \multicolumn{2}{|c|}{ **** } & \multicolumn{2}{|c|}{ * } \\
\hline Concn $\times$ thinning & \multicolumn{2}{|c|}{ NS } & \multicolumn{2}{|c|}{ NS } & \multicolumn{2}{|c|}{ NS } & \multicolumn{2}{|c|}{ NS } \\
\hline
\end{tabular}

NS,*,***Nonsignificant or significant at $P=0.05$ or 0.001 , respectively.

Table 2. Stepwise regression for shelf life of cucumbers $(n=1529$ fruit $)$.

\begin{tabular}{lrccc}
\hline \hline Variable & Coefficient & SE & $\begin{array}{c}\text { Partial } \\
R^{2}\end{array}$ & $P>\mathrm{F}$ \\
\hline Intercept & -19.4274 & & & \\
Fruit color & 6.0691 & 0.33721 & 0.2336 & 0.0001 \\
Days to harvest & -0.2483 & 0.03055 & 0.0339 & 0.0001 \\
Fresh wt & -0.0042 & 0.00138 & 0.0051 & 0.0012 \\
Residual SD $=5.4723$ & & & & \\
\hline
\end{tabular}

reduced the days to harvest and marketable fruit per plant.

With individual fruit ( $\mathrm{n}=1529$ fruits), shelf life was positively correlated with fruit color at harvest $(r=0.48, P=0.0001)$, and negatively correlated with days to harvest $(r=-0.34, P=0.0001)$. The shelf life was not correlated with fresh weight at harvest $(r=-0.01, P=0.7051)$. Fruit color at harvest was indicative of potential shelf life, accounting for $23 \%$ of variability in shelf life (Table 2).

Fruit shelf life increased with nodal position (node number) on the main stem (Fig. 1), fluctuated on the first laterals, and decreased on the second laterals.

Greenhouse production conditions affected postharvest shelf life of long English cucumbers. Shelf life, based only on surface color, was increased by a high macronutrient concentration, probably through enhanced fruit color at harvest. Increasing the macronutrient concentration increased solution EC, which has been reported to result in longer shelf life in cucumber (Aalbersberg, 1984). The high EC of nutrient solutions also has been noted to improve other aspects of fruit quality, such as flavor and percentage dry matter in tomato (Ehret and Ho, 1986; Mizrahi et al., 1988). The overall concentration of nutrient solutions influences cytokinin level (Kuiper et al., 1989), which is well known to affect chlorophyll concentrations. Chlorophyll synthesis and retention are enhanced by high $\mathrm{N}$ concentration (Epstein, 1972; Leopold and Kriedemann, 1975).

Thinned plants produced fewer fruit with a longer shelf life, suggesting a possible role for plant source/sink relationships. Schapendonk and Challa (1980) illustrated the relationship between sink activity of cucumber fruit and source activity of leaves. An increased source: sink ratio may facilitate longer shelf life through an increased fruit growth rate, since days to harvest was found to be inversely related to shelf life (Lin, 1989). Fruit thinning was intended to reduce mar- ketable yield by one-third. However, the difference in marketable yield between thinned and nonthinned treatments was only $10 \%$. This lessening of the difference was probably due to the high rates of self-thinning (fruit abortion) and fruit curling on nonthinned plants, which would reduce the number of marketable fruit and result in less-than-expected differences between treatments.

The physiological age of cucumber fruit appears to have a strong influence on shelf life as shown by the negative correlation between shelf life and days to harvest (Table 2). Kanellis et al. (1986) also reported that postharvest shelf life declined with increasing age at which the fruit was harvested. It would be reasonable to hypothesize that any factors that allow rapid fruit growth would result in younger fruit at harvest with longer shelf life. The present experiment was not specifically designed to answer this question. The results obtained in this experiment, however, seem to support this probability. Both high nutrient concentration and fruit thinning reduced the number of marketable fruit, reduced days to harvest (i.e., promoted rapid growth), and increased shelf life (Table $1)$.

Shelf life varied among cucumbers harvested from the different nodal locations in the plant canopy. This might have been due to the light conditions under which fruit developed. Cucumbers harvested from the top of the main stem and second laterals had longer shelf life than those harvested from the bottom of the canopy. However, this relationship was not observed with fruit harvested from the first laterals. In addition, there was no consistent relationship between shelf life and prevailing light during which these fruit developed (data not shown), demonstrating the difficulty in relating seasonal light conditions to shelf life on a chronological basis.

Fruit color at harvest was indicative of potential shelf life. The relationship between shelf life and fruit color at harvest may be commercially useful in the prediction of the duration of fruit marketability. For example, dark green fruit at picking may not have to be moved through the warehousing and distribution systems as quickly as paler fruit. Conversely, light green fruit should be marketed shortly after harvest.

This study illustrates that the quality of long English cucumbers can be improved through elevated fertilizer concentrations and reduced fruit load per plant, but at the expense of yield. Manipulation of the level of fertilization may be useful in meeting the specific production demands of either high yield or high quality.

\section{Literature Cited}

Aalbersberg, Y.W. 1984. Growth and production depend on calcium and EC (in Dutch). Tuinderij 64(19):28-31.

Ehret, D.L. and L.C. Ho. 1986. The effects of salinity on dry matter partitioning and fruit growth in tomatoes grown in nutrient film culture. $\mathrm{J}$. Hort. Sci. 61:361-367.

Epstein, E. 1972. Mineral nutrition of plants: principles and perspectives. Wiley, New York.

Grower: 1988. Criteria for quality. Grower 110(8):13-15.

Kanellis A. K., L.L. Morris, and M.E. Saltveit. 1986. Effect of stage of development on postharvest behavior of cucumber fruit. HortScience 21:1165-1167.

Kuiper, D., P.J.C. Kuiper, H. Lambers, J. Schuit, and M. Staal 1989. Cytokinin concentration in relation to mineral nutrition and benzyladenine treatment in Plantago major ssp. pleiosperma. Physiol. Plant 75:511-517.

Leopold, A.C. and P.E. Kreidemann. 1975. Plant growth and development. McGraw-Hill, New York.

Lin, W.C. 1989. Cucumber yellowing -A challenge for quality. Proc. 5th Intl. Controlled Atmosphere Conf., Wenatchee, Wash. 2:126-133.

Mizrahi, Y., E. Taleisnik, V. Kagan-Zur, Y. Zohar, R. Offenback, E. Matan, and R. Golan. 1988. A saline irrigation regime for improving tomato fruit quality without reducing yield. J. Amer. Soc. Hort. Sci. 113:202-205.

Poenicke, E. F., S.J. Kay, D.A. Smittle, and R.E Williamson. 1977. Ethylene in relation to postharvest quality deterioration in processing $\mathrm{cu}-$ cumbers. J. Amer. Soc. Hort. Sci. 102:303306.

Saltveit, M.E. and R.F. McFeeter. 1980. Polygalacturonase activity and ethylene synthesis during cucumber fruit development and maturation. Plant Physiol. 66:1019-1023.

Schapendonk, A.H.C.M. and H. Challa. 1980 Assimilate requirements for growth and maintenance of the cucumber fruit. Acta Hort. 118:73-82. 